\title{
Dimitrij Bumazhnov, Emmanouela Grypeou, Timothy B. Sailors, Alexander Toepel (eds). Bibel, Byzanz und Christlicher Orient. Festschrift für Stephen Gerö zum 65. Geburtstag.
}

Florence Jullien

\section{(2) OpenEdition \\ Journals}

Édition électronique

URL : http://journals.openedition.org/abstractairanica/41306

DOI : $10.4000 /$ abstractairanica.41306

ISSN : 1961-960X

Éditeur :

CNRS (UMR 7528 Mondes iraniens et indiens), Éditions de l'IFRI

Référence électronique

Florence Jullien, « Dimitrij Bumazhnov, Emmanouela Grypeou, Timothy B. Sailors, Alexander Toepel (eds). Bibel, Byzanz und Christlicher Orient. Festschrift für Stephen Gerö zum 65. Geburtstag. », Abstracta Iranica [En ligne], Volume 34-35-36 | 2017, document 9, mis en ligne le 15 juillet 2016, consulté le 03 octobre 2020. URL : http://journals.openedition.org/abstractairanica/41306 ; DOI : https://doi.org/ 10.4000/abstractairanica.41306

Ce document a été généré automatiquement le 3 octobre 2020.

Tous droits réservés 


\section{Dimitrij Bumazhnov, Emmanouela Grypeou, Timothy B. Sailors, Alexander Toepel (eds). Bibel, Byzanz und Christlicher Orient. Festschrift für Stephen Gerö zum 65. Geburtstag.}

Florence Jullien

\section{RÉFÉRENCE}

Dimitrij Bumazhnov, Emmanouela Grypeou, Timothy B. Sailors, Alexander Toepel (eds). Bibel, Byzanz und Christlicher Orient. Festschrift für Stephen Gerö zum 65. Geburtstag. Louvain, Peeters, 2011, 683 p. (Orientalia Lovaniensia Analecta 187)

1 Ce volume offert en hommage à Stephen Gerö (Université de Tübingen) par ses collègues et étudiants est le reflet de la richesse de ses centres d'intérêt thématiques et de sa production scientifique, autour des langues et des cultures des communautés chrétiennes du Moyen-Orient. Parmi les 36 contributions réunies, plusieurs ont trait au christianisme en milieu syriaque, caucasien ou arabe, avec des ouvertures vers l'Égypte et la Nubie, l'Asie centrale et Byzance. On trouvera également une bibliographie exhaustive des œuvres de l'A. en ouverture. 


\section{AUTEURS}

\section{FLORENCE JULLIEN}

CNRS, Mondes iranien et indien, Paris 